\title{
Awake video assisted thoracic surgery series report
}

\author{
A Klijian*, N Andonian \\ From 23rd World Congress of the World Society of Cardio-Thoracic Surgeons \\ Split, Croatia. 12-15 September 2013
}

\section{Background}

Traditionally, video-assisted thoracic surgery (VATS) is performed under general anesthesia with selective ventilation and endotracheal intubation. Although some sparse data exists on VATS under local anesthesia, most series reserve this technique for pleural-based surgery. This technique includes more complex procedures, with results that surpass traditional open thoracotomies.

\section{Methods}

This case study analyzed 196 patients who underwent awake thoracic surgery from June 2010 to October 2012. This single surgeon experience includes wedge resections, lobectomies, decortications, pleural biopsies, pleurodesis, bullectomies and pericardial windows.

\section{Results}

Of the 196 cases, sixty were wedge resections, with an average length of hospital stay (ALS) of 1.5 days. ALS for the 38 decortications was 2.5 days, for the 28 pleural biopsies was 1 day. There were 36 mechanical and talc pleurodesis for recurrent effusions, 30 of them malignant, having an ALS of 1.5 days. Two pericardial windows were performed, with an ALS of 1.5 days. Twenty-two patients had lobectomies for malignancies (6 left upper lobes, 7 left lower lobes, 5 right upper lobes, 1 right middle lobe, 2 right lower lobes and 1 left lower lobe with lingulectomy), with an ALS of 1.8 days.

\section{Conclusions}

The results of operating under local anesthesia with sedation provide comparable, if not better, post-operative results. By choosing not to subject patients to general anesthesia with an endotracheal tube and one lung ventilation, as well as providing a lung sealant $\left(\right.$ Progel $\left.^{\mathbb{R}}\right)$,

* Correspondence: klijian@hotmail.com

Sharp \& Scripps Healthcare, San Diego, CA, USA we shortened the average hospital stay, provided quicker recovery times, better patient satisfaction and presumably cost savings. We recommend that surgeons experienced in VATS procedures attempt to operate while their patients are merely sedated. And if that emergent intubation were required, necessary equipment, personnel and patient positioning are taken into consideration before beginning the procedure.

Published: 11 September 2013

doi:10.1186/1749-8090-8-S1-O243

Cite this article as: Klijian and Andonian: Awake video assisted thoracic surgery series report. Journal of Cardiothoracic Surgery 2013 8(Suppl 1): $\mathrm{O} 243$.

Submit your next manuscript to BioMed Central and take full advantage of:

- Convenient online submission

- Thorough peer review

- No space constraints or color figure charges

- Immediate publication on acceptance

- Inclusion in PubMed, CAS, Scopus and Google Scholar

- Research which is freely available for redistribution 